Research Journal of Biological Sciences 14 (3-6): 66-70, 2019

ISSN: $1815-8846$

(C) Medwell Journals, 2019

\title{
Follicular and Luteal Phases of Estrus Cycle of Tapri and Mixed Goats Under Semi Intensive Management System
}

\author{
Faiza Rubab \\ Department of Animal Reproduction, Sindh Agriculture University, Tando Jam, Pakistan
}

\begin{abstract}
Follicular and luteal phases of estrus cycle of Tapri and mixed goats under semi intensive management system. In order to get insight to understand the mechanism of steroidogenesis and study of various phases of estrus cycle in highly prolific Tapri goats of Sindh, in first phase an attempt was made to determine the length of various phases of estrus cycle of Tapri breed and its comparison with cross breed goats during three estrus cycles. Total ten healthy adult cycling goats (five from each breed) were maintained at the departments of animal reproduction and livestock management, FAHVS, SAU, Tandojam. Vaginal cytology method was used as marker to determine the status of estrus cycle. It was found that mean length of estrus cycle in tapri and cross breed goats were $21.32 \pm 0.26$ and $21.2 \pm 0.56$ days, respectively, both the longest (22.2 \pm 0.67 days) and shortest ( $20.4 \pm 0.66$ days) duration of estrus cycles length were found in cross breed. The length of follicular phase including the estrus was $1.48 \pm 0.07,1.34 \pm 0.01$ days and during proestrus period it was $2.98 \pm 0.01$ and $3.20 \pm 0.1$ days in tapri breed and cross breed respectively, similarly, during luteal phase the length of metestrus and diestrus were in tapri versus cross breed goats were $3.25 \pm 0.14$ vs $3.28 \pm 0.6$ and $13.59 \pm 0.10$ vs $13.28 \pm 0.4$ days, respectively.
\end{abstract}

Key words: Goat, estrus cycle, Tapri, Sindh, luteal phase

\section{INTRODUCTION}

There are nine recognized breeds of goats in Sindh among 34 recognized goat breeds in Pakistan (Devendra et al., 1997). There are many breeds of goats (Capra hircus) found in Sindh such as Pateri, Kamori, Bari, Bugri, Kohistani or Jabli, Jattan, Tharki, Teddy and Tapri (Shah, 1994). The Tapri breed of Sindh province is small sized breed and is highly prolific with highest fertility, superior skin quality, early puberty, smallest kidding interval and well adaptability in certain conditions. Tapri goat is also called as Lappi, found in many parts of Hyderabad, Sanghar, Mirpurkhas and Khairpur districts of Sindh. These goats are considered primarily as meat breed but it can be also utilized for milk purpose (Khan et al., 2008). It has a small size but are famous for twin birth and early maturity, their adult male and female weighs about 25 and $20 \mathrm{~kg}$, respectively (Shah, 1994). The most important traits from economy point of views especially, in small ruminants including goats are the prolificacy. The farmers prefer the breeding in a way to get 2-3 kids per year, the pattern of number of birth is different from species to species, some breed preferably gives single kid and other may 2-3 normally. Generally, the Dwarf goats are highly prolic and non-seasonal, having distinct traits in their reproductive cycle which differentiate this breed from other various goat breeds. In Black Bengal goats the higher prolificacy rate has been found at the average of 1.8 kids born per female goat (unpublished data), this birth rate is comparable with other highly prolific goat breeds of the world including Nubian (2.0 kids), Pygmy and American Alpine (1.9 kids), French Alpine and Saanen (1.7 kids) and Toggenburg (1.6 kids). There is no information on Tapri goat breed of Sindh Pakistan on that aspect.

The level of reproductive performance is dependent on the interaction of genetic and environmental factors but this performance is particularly susceptible to the temperature and seasonal factors. The availability of season related nutrients also affect the reproduction. The reproduction efficiency in female goats is determined by many different processes including length of the breeding season, cyclic activity of the animal, rate of ovulation, fertilization rate and anestrous of post-partum period and the other factors such as proper growth and viability of the young one. Reproductive efficiency may also be determined and expressed as the birth rate, time and weaning rate, interval of kidding, newly born kid's live weight and the length of duration of the reproductive cycle (Grayling 1988).

There are many techniques of estrus detection such as vaginal pH-metery, fern pattern of cervical mucus discharge, changes in behavioral signs, milk yield fluctuation, heat expectancy charts, bio-stimulation, electronic odour detector, milk progesterone and estrogen detection, ultrasonography, use of vasectomized buck, estrus synchronization and exfoliative vaginal cytology (Colpocytology) (Rao et al., 2013). Exfoliative vaginal 
cytology and estrus synchronization are techniques capable of improving the reproductive potential of livestock (Kumar et al., 2013).

Keeping in view the importance of higher prolificacy of Tapri goat breed, it is very much needed that knowledge of various phases of estrus cycle and determination of complete estrus cycle length is important to get insight into the steriodogenesis. In the first attempt with the first step to set very basic information specially the plasma progesterone concentration in Tapri breed with comparison of crossbreed goats is very much needed. These may provide the baseline for understanding the dynamics of follicles and hormonal secretion in high prolific Tapri breed such information is lacking and therefore, this study was designed with objective of determination of the time duration of various phases of estrus cycle of goats.

\section{MATERIALS AND METHODS}

Management of experimental animals: Ten apparently healthy each of Tapri and mixed cross goat breeds divided into two groups, i.e., group A consisting of Tapri breed and group B consisting of mixed cross breed goats, each group had five number of goats. These animals were kept under semi intensive management system and were fed on leafy twigs of herbs, shrubs, small trees (natural grazing) in day time and other leguminous plants such as Lucerne or berseem in night along with concentrate mixture (35\% wheat bran, $30 \%$ crushed maize, $10 \%$ rice husk, $20 \%$ soybean meal) throughout the experimental phase. Water was providedad libitum to all experimental animals throughout the research workat the Departments of Animal Reproduction and Livestock Management, Faculty of Animal Husbandry and Veterinary Sciences, Sindh Agriculture University, Tandojam. The study was conducted between September, 2016 to February, 2017.

Confirmation of estrus cycle status: The vaginal smears were collected from all animals for exfoliated vaginal cytology, the next expected phases of estrus cycle in all animals were determined by cell type and close observation of animals during 8.30 am to $15.00 \mathrm{pm}$ for signs of estrus and other activities. After documenting the confirmed estimated phases of estrus cycle in animals they were allowed for another next two other normal estrus period to determine the average length of various phases and their duration during estrus cycle. The study of cell type and their results which were used as marker for determining the phases of estrus cycles and their duration are attached as Annexure-1. After proper confirmation of the estrus cycle length and duration of each phase the samples from animals were collected accordingly on prescribed proforma as follows:

Four samples from each goat during estrus cycle were collected for three consecutive estrus cycles. Total of 120 samples from 10 goats for three consecutive estrus cycles were processed for plasma separation. During each estrus cycle the samples were collected on day 1 , day 4 , day 7 , day 10 and day 15 of estrus cycle.

Sample collection: Vaginal smears were taken daily for three consecutive estrus cycles, 21 days each cycle, from ten goat does using 8 inches sterile small ruminant vaginal swabs. The swabs were earlier moistened in normal saline to avoid irritation to the vaginal lumen and to get adequate load of exfoliative vaginal cells. Each goat doe was well controlled in standing position with the help of an assistant and the perineum and vulva were washed with fresh clean water and dried with a clean towel. A six-inched sterile wet cotton swab was smoothly introduced into the vaginal opening with the help of right hand while the left thumb and fore-finger were used to open the lips of vulva, ensuring that the swab was inserted many inches preceding the vulva into the vagina. Once the swab was fully inserted, it was rotated at least $90-180^{\circ}$ gently against the vaginal mucosa 2-3 times, leaving few seconds to allow the animal to relax and was then withdrawn smoothly. This process was also done to ensure that the cotton swab was able to gain adequate quantity of cells needed for microscopic observation.

Smear making: Each frosted glass slide was initially labelled with tag number of female Tapri goat and date of sample collection for getting proper record. To prevent imprints the glass slides were hold from lateral borders and the collected vaginal swab samples were immediately smeared by gentle rolling of the swab along the length of the labelled frosted glass slides. Two to three horizontal streaks were sufficient for getting proper vaginal exfoliative cells load. The smeared slides were dried in the air and were immediately brought to the laboratory for fixation to avoid shrinkage and degeneration of exfoliated vaginal cells, at the department of Animal Reproduction, Faculty of Animal Husbandry and Veterinary Sciences, Sindh Agriculture University, Tando Jam.

Fixation of the sample: After drying the smeared slides in the air for few minutes, it was necessary to fix the slide before staining to avoid water absorption or shrinkage of the exfoliative vaginal epithelial cells and to prevent washing of these cells during staining. Therefore, the prepared slides were immediately fixed in absolute (100\%) methanol (Merck specification) for not $<5 \mathrm{~min}$ and were allowed to dry in the air. The slides were then ready for staining procedure.

Staining of the slides: After fixation, the slides were stained with readymade Geimsa (Merck specie) in a glass beaker. The slides were immersed in the glass jar containing Giemsa stain for three to five minutes and then 
removed for further processing. Three to five min staining with Giemsa stain produced the most ideal specimen for microscopic observation. To avoid contamination with vaginal cells from previous preparations the stain was regularly replaced and filtered with filter paper. Further characterizations were followed as described by Ziaullah (2016).

\section{RESULTS AND DISCUSSION}

The present study was carried out on total 10 female Tapri and mixed crossbreeds goats maintained at the departments of Animal Reproduction and Livestock Management, Faculty of Animal Husbandry and Veterinary Sciences, Sindh Agriculture University Tandojam to determine the progesterone level, length of estrus cycle and to compare the progesterone level of both breeds for three consecutive estrus cycles.

Length of estrus cycle in Tapri and cross breed goats: Results presented in Table 1 demonstrate the mean length of estrus cycle in Tapri and cross breed goats were $21.32 \pm 0.26$ and $21.06 \pm 0.56$ days, respectively. Longest estrus cycle was $22.2 \pm 0.67$ days and shortest length was $20.4 \pm 0.66$ days were found in cross breed. Statistically non-significant difference $(\mathrm{p}>0.05)$ was observed during the estrus cycle of both breeds.

Results presented in Table 2 demonstrate the mean duration of estrus phases in Tapri and cross breed goats were $1.48 \pm 0.07$ and $1.34 \pm 0.01$ days respectively Statistically significant difference ( $>0.05$ ) was observed during the estrus cycle of both breeds.

Duration of metestrus phases in Tapri and cross breed goats: Results presented in Table 3 demonstrate the mean duration of metestrus phases in Tapri and cross breed goats were $3.25 \pm 0.14$ and $3.28 \pm 0.6$ days, respectively Statistically non-significant difference $(\mathrm{p}>0.05)$ was observed during the estrus cycle of both breeds.

Duration of diestrus phases in Tapri and cross breed goats: Results presented in Table 4 demonstrate the mean duration of diestrus phases in Tapri and cross breed goats were $13.59 \pm 0.10$ and $13.28 \pm 0.4$ days, respectively Statistically non-significant difference $(p>0.05)$ was observed during the estrus cycle of both breeds. Values with same superscript with rows indicate non-significant difference.

Duration of proestrus phases in Tapri and cross breed goats: Results presented in Table 5 demonstrate the mean duration of diestrus phases in Tapri and cross breed goats were $2.98 \pm 0.01$ and $3.20 \pm 0.1$ days, respectively. Statistically non-significant difference $(p>0.05)$ was observed during the estrus cycle of both breeds.

This is the first study which compares circulating plasma progesterone hormone concentrations in native Tapri goat breed and indigenous crossbreed (Kamori $\mathrm{x}$ Teddy) goats during the estrus cycle. Furthermore, there

Table1: Length of estrus cycles in Tapri and cross breed goats

\begin{tabular}{|c|c|c|c|c|c|c|}
\hline \multirow[b]{3}{*}{ Estrus cycles } & \multicolumn{6}{|c|}{ Length of estrus cycle (Days) } \\
\hline & \multicolumn{3}{|l|}{ Tapri $(\mathrm{N}=5)$} & \multicolumn{3}{|c|}{ Cross breed $(\mathrm{N}=5)$} \\
\hline & Estrus cycle 1 & Estrus cycle 2 & Estrus cycle 3 & Estrus cycle 1 & Estrus cycle 2 & Estrus cycle 3 \\
\hline $\begin{array}{l}\text { Average } \\
\text { Means } \pm \text { SE }\end{array}$ & $21.32 \pm 0.26^{\mathrm{a}}$ & $21.7 \pm 0.94$ & $20.8 \pm 0.84$ & $21.06 \pm 0.56^{\mathrm{a}}$ & $20.6 \pm 0.99$ & $22.2 \pm 0.67$ \\
\hline & \multicolumn{6}{|c|}{ Duration of estrus (Days) } \\
\hline & \multicolumn{3}{|l|}{ Tapri (N = 5) } & \multicolumn{3}{|c|}{ Cross breed $(\mathrm{N}=5)$} \\
\hline Estrus cycles & Estrus cycle 1 & Estrus cycle 2 & Estrus cycle 3 & Estrus cycle 1 & Estrus cycle 2 & Estrus cycle 3 \\
\hline $\begin{array}{l}\text { Average } \\
\text { Means } \pm \text { SE }\end{array}$ & $\begin{array}{l}1.47^{\mathrm{a}} \\
1.48 \pm 0.07^{\mathrm{a}}\end{array}$ & $1.32^{\mathrm{a}}$ & $1.65^{\mathrm{a}}$ & $\begin{array}{l}1.33^{\mathrm{b}} \\
1.34 \pm 0.01^{\mathrm{b}}\end{array}$ & $1.22^{\mathrm{b}}$ & $1.47^{\mathrm{b}}$ \\
\hline \multicolumn{7}{|c|}{ Values with different superscript with rows differ significantly at $\mathrm{p}<0.05$} \\
\hline & \multicolumn{6}{|c|}{ Duration of metestrus (Days) } \\
\hline & \multicolumn{3}{|l|}{ Tapri (N = 5) } & \multicolumn{3}{|c|}{ Cross breed $(\mathrm{N}=5)$} \\
\hline Estrus cycles & Estrus cycle 1 & Estrus cycle 2 & Estrus cycle 3 & Estrus cycle 1 & Estrus cycle 2 & Estrus cycle 3 \\
\hline $\begin{array}{l}\text { Average } \\
\text { Means }+ \text { SF }\end{array}$ & $\begin{array}{l}3.09 \pm 0.20 \\
3.25+0.14^{\mathrm{a}}\end{array}$ & $3.54 \pm 0.06$ & $3.12 \pm 0.05$ & $\begin{array}{l}3.20 \pm 0.20 \\
3.28+0.06^{\mathrm{a}}\end{array}$ & $3.24 \pm 0.13$ & $3.40 \pm 0.24$ \\
\hline
\end{tabular}

Values with same superscript with rows indicate non-significant difference 
Res. J. Biol. Sci., 14 (3-6): 66-70, 2019

Table 4: Duration of diestrus phases in Tapri and cross breed goats

\begin{tabular}{|c|c|c|c|c|c|c|}
\hline \multirow[b]{3}{*}{ Estrus cycles } & \multicolumn{6}{|c|}{ Duration of diestrus (Days) } \\
\hline & \multicolumn{3}{|l|}{ Tapri $(\mathrm{N}=5)$} & \multicolumn{3}{|c|}{ Cross breed $(\mathrm{N}=5)$} \\
\hline & Estrus cycle 1 & Estrus cycle 2 & Estrus cycle 3 & Estrus cycle 1 & Estrus cycle 2 & Estrus cycle 3 \\
\hline Average & $13.59 \pm 0.41$ & $13.78 \pm 0.29$ & $13.4 \pm 0.08$ & $13.28 \pm 0.11$ & $13.20 \pm 0.08$ & $13.36 \pm 0.16$ \\
\hline Means \pm SE & $13.59 \pm 0.10^{\mathrm{a}}$ & $13.28 \pm 0.4^{\mathrm{a}}$ & & & & \\
\hline
\end{tabular}

Table 5: Duration of proestrus phases in Tapri and cross breed goats

\begin{tabular}{|c|c|c|c|c|c|c|}
\hline \multirow[b]{3}{*}{ Estrus cycles } & \multicolumn{6}{|c|}{ Duration of proestrus (Days) } \\
\hline & \multicolumn{3}{|l|}{ Tapri $(\mathrm{N}=5)$} & \multicolumn{3}{|c|}{ Cross breed $(\mathrm{N}=5)$} \\
\hline & Estrus cycle 1 & Estrus cycle 2 & Estrus cycle 3 & Estrus cycle 1 & Estrus cycle 2 & Estrus cycle 3 \\
\hline Average & $2.98 \pm 0.15$ & $3.00 \pm 0.0$ & $2.96 \pm 0.02$ & $3.20 \pm 0.20$ & $3.18 \pm 0.09$ & $3.22 \pm 0.11$ \\
\hline
\end{tabular}

Values with same superscript with rows indicate non-significant difference

are only few reports with the same experimental design in other breeds and assays during particular time of reproductive cycle has been reported so far in domestic goats like dwarf and other breed (Bukar et al., 2012; Khanum et al., 2007; Zarkawi and Soukouti, 2001), therefore, this study provide an opportunity to investigate endocrinological and physiological differences between various hormones and way forward to study the morphology of ovaries in domestic goats during reproductive cycle of highly prolific domestic goats.

The length of estrous cycle in does is affected by many factors, during present study the mean length of estrus cycle in Tapri and cross breed goats were $21.32 \pm 0.26$ and $21.06 \pm 0.56$ days, respectively, the results of present study for estrus cycle length of both breeds fall in findings observed by Browning, also, in the line of present results the normal mean duration of Nubian goat breed estrous cycle of 21.5 days has been reported, similarly, Gonzalez-Stagnaro and Madrid-Bury (1982) reported the interestrus interval of the Venezuelan tropical goat and was about 21 days. The observation of present study are comparable with the findings of Kunbhar et al. (2016) and Fakruzzaman et al. (2012) who reported 21.03 and 21.33 days as an average estrus cycle length in Kamohri and Bengal goats respectively. The results of Simplicio et al. (1986) are also support the present result who reported an average length of 21.2 days in goats. In Damascus goats, the length of estrous cycle was reported as $21.2 \pm 1.5$ days (Zarkawi and Soukouti, 2001). Chemineau et al. observed that the length of estrous cycle in Alpine goats was 20.2 days which is in agreement with the present research data. Otchere and Nimo (1975) reported the average length of estrus cycle as 20.9 days in 4 year old West African Dwarf goats. Parallel with current findings the average length of estrous cycles in goats was 20.9 days as described by Aurion which showed similarity with the present findings. Minor variation in length of estrus cycle than the current study has been observed by Babumathi and Mukherjee (1981) who reported an average length of estrous cycle as $19.6 \pm 0.04$ days, also, in West African Dwarf goats the mean estrus cycle length of $18.3 \pm 1.6$ days has been observed by Akusu and Ajala (2000).

The higher length of about 24 days cycle length for the Pygmy goat of estrus cycle has been reported by Jarosz et al. (1971). The length of estrus cycle is recognized and reported which ranged in between 19-24 days in various breeds of goat (Bukar et al., 2012; Khanum et al., 2007; Zarkawi and Soukouti, 2001). Corteel et al. (1982), Gonzalez-Stagnaro and Madrid-Bury (1982) and Van Rensburg (1971) reported a seasonally dependent effect on reproductive cycle has been reported by many researchers. The shortest duration of $22 \mathrm{~h}$ for the Angora goat for sexual receptivity has been observed by Van Rensburg (1971), the duration of estrus reported in this breed is 2.8 days and higher duration of estrus, i.e., 96 hours in Pygmy strain has been reported by Jarosz et al. (1971) reported the longest duration.

The events of the estrous cycle are largely controlled by the hormonal interactions of the ovaries with the secretory glands (pituitary, hypothesis) located at the base of the brain. In addition, to internal stimuli, this system is also responsive to external stimulation such as changes in day length and the presence and absence of males. In short, primary follicles in the ovaries, containing primary oocytes (eggs), develop in successive waves to develop Graafian follicles that will rupture and release a secondary oocyte during ovulation. The development of the follicle is under the control of gonadotropins (follicle stimulating hormone and luteinizing hormone) released by the pituitary gland. The variations compare to present results with mentioned researchers might be due to breed variation, environmental factors and nutritional regime of the different goat breeds. The difference in length of estrus cycle in goats may be due to environmental stressors, breed, climate (heat, cold, wind and humidity), nutrition (feeds, feeding systems) and management (housing density and conditions, transportation, weaning practices) etc. 
Res. J. Biol. Sci., 14 (3-6): 66-70, 2019

\section{CONCLUSION}

It was concluded from this study that statistically non-significant difference was observed in length of various phases of estrus cycles in both goat breeds.

\section{REFERENCES}

Akusu, M.O. and O.O. Ajala, 2000. Reproductive performance of West African Dwarf goats in the humid tropical environment of Ibadan. Isr. J. Vet. Med., 55: 2000-2000.

Babumathi, T. and T.K. Muhgerjee, 1981. Estrus cycle length and estrus behavior studies in the Kambing Katjang (Goats). Master Thesis, Department of Genetics and Cellular Biology, University of Malaya, Kuala Lumpur, Malaysia.

Bukar, M.M., R. Yusuf, A.W. Haroon, G.K. Dhaliwal, M.A.G. Khan and M.A. Omar, 2012. Estrus response and follicular development in boer does synchronized with flagstone acetate and PGF2a or their combination. Trop. Anim. Health Prod., 44: 1505-1511.

Corteel, J.M., C. Gonzalez and J.F. Nunes, 1982. Research and development in the control of reproduction (Goats). Proc. Int. Conf. Goat Prod. Dis., 1: 584-601.

Devendra, C., D. Thomas, M. Jabbar and H. Kudo, 1997. Improvement of Livestock Production in Crop-Animal Systems in Rainfed Agro-Ecological Zones of South-East Asia. International Livestock Research Institute (ILRI), Nairobi, Kenya, ISBN: 92-9146-031-1, Pages: 166.

Fakruzzaman, M., Q.S. Akter, S.S. Husain, M.A.M.Y. Khandoker, A.S. Apu and M.R. Islam, 2012. Estrus characteristics of black bengal does under intensive condition. Iran. J. Applied Anim. Sci., 2: 89-95.

Gonzalez-Stagnaro, C. and N. Madrid-Bury, 1982. Sexual season and estrous cycle of native goats in a tropical zone of Venezuela. Proceedings of the 3rd International Conference on Goat Production and Disease, January 10-15, 1982, University of Arizona, Tucson, Arizona, USA., pp: 3-11.

Greyling, J.P.C., 1988. Certain aspects of Reproductive physiology in the Boer goat doe. B.Sc. Thesis, University of Stellenbosch, South Africa.
Jarosz, S.J., R.J. Deans and W.R. Dukelow, 1971. The reproductive cycle of the African pygmy and toggenburg goat. Reproduction, 24: 119-123.

Khan, M.S., M.A. Khan and S. Mahmood, 2008. Genetic resources and diversity in Pakistani goats. Int. J. Agric. Biol., 10: 227-231.

Khanum, S.A., M. Hussain and R. Kausar, 2007. Assessment of reproductive parameters in female Dwarf goat (Capra hircus) on the basis of progesterone profiles. Animal Rep. Sci., 102: 267-275.

Kumar, P., S. Rao, T.K. Kumar, N. Chaurasia, S. and N.B. Patel, 2013. Heat detection techniques in cattle and buffalo. Vet. World, 6: 363-369.

Kunbhar, H.K., A.A. Memon, A.L. Bhutto, Z.I. Rajput, V. Suthar, A. Memon and R.A. Leghari, 2016. Study on female reproductive performance of Kamohri goat managed under traditional management conditions in district Hyderabad, Sindh, Pakistan. Int. J. Adv. Res. Biol. Sci., 3: 251-260.

Leigh, O.O., A.K. Raheem and O.J.A. Oluwadamilare, 2010. Improving the reproductive efficiency of the goat: Vaginal cytology and vulvar biometry as predictors of synchronized estrus/breeding time in West African dwarf goat. Int. J. Morphol., 28: 923-928.

Otchere, E.O. and M.C. Nimo, 1975. Observations on the reproductive behaviour in the West African Dwarf goat. Ghana J. Agric. Sci., 8: 187-190.

Shah, S.I., E.L Bashir and R. Bantel, 1994. Animal Husbandry. National Book Foundation, Islamabad, Pakistan, Pages: 416.

Simplicio, A.A., G.S. Riera, S. Nunes and W.C. Foote, 1986. Frequency and duration of oestrous cycle and period in genetically non-descript (SRD) type of goats in the Tropical Northeast of Brazil. Pesquisa Agropecuaria Bras. Brasilia, 21: 535-540.

Van Rensburg, S.J., 1971. Reproductive physiology and endocrinology of normal and habitually aborting Angora goats. Onderstepoort J. Vet. Res., 38: 1-62.

Zarkawi, M. and A. Soukouti, 2001. Serum progesterone levels using radioimmunoassay during oestrous cycle of indigenous Damascus does. N. Z. J. Agric. Res., 44: 165-169.

Ziaullah, 2016. Evaluation of exfoliative vaginal cytology during estrus cycle of Tapri goat. M.Phil Thesis, Sindh Agriculture University, Tando Jam. 